\title{
Microemulsion synthesis of nano-sized calcium sulfate hemihydrate and its morphology control by different surfactants
}

Shun Chen ${ }^{1}$, Yan $\mathrm{Xu}^{1}$, Xingyang $\mathrm{He}^{1}$, Ying $\mathrm{Su}^{*}{ }^{1}$, Jin Yang ${ }^{1}$, Wei Chen ${ }^{1}$, Hongbo Tan ${ }^{2}$

1 School of Civil Engineering, Architecture and Environment, Hubei University of Technology,

Wuhan, China

2 State Key Laboratory of Silicate Materials for Architecture, Wuhan University of Technology, Wuhan, China

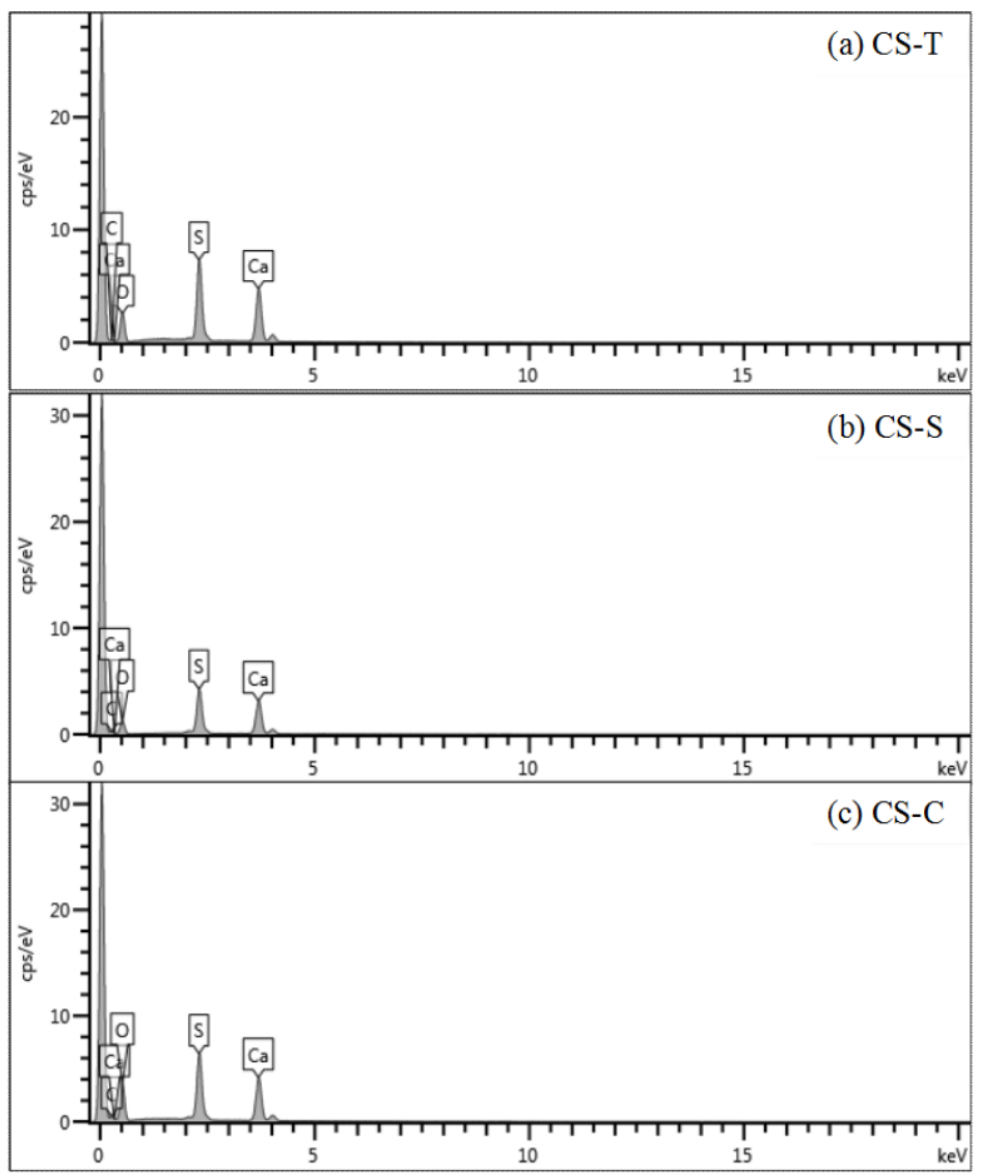

Figure S1. EDX spectra of samples CS-T (a), CS-S (b) and CS-C (c) 


\begin{tabular}{|c|c|c|c|c|}
\hline Samples & Element & wt $\%$ & $\begin{array}{c}\text { wt\% } \\
\text { Sigma }\end{array}$ & Atomic percent \\
\hline \multirow{5}{*}{ (a) $\mathrm{CS}-\mathrm{T}$} & $\mathrm{C}$ & 20.56 & 1.39 & 32.86 \\
\hline & $\mathrm{O}$ & 37.02 & 0.73 & 44.43 \\
\hline & S & 19.95 & 0.38 & 11.94 \\
\hline & $\mathrm{Ca}$ & 22.48 & 0.43 & 10.77 \\
\hline & total: & 100.00 & & 100.00 \\
\hline \multirow{5}{*}{ (b) $\mathrm{CS}-\mathrm{S}$} & $\mathrm{C}$ & 28.24 & 1.47 & 43.69 \\
\hline & $\mathrm{O}$ & 29.98 & 0.76 & 34.83 \\
\hline & $\mathrm{S}$ & 18.17 & 0.42 & 10.53 \\
\hline & $\mathrm{Ca}$ & 23.61 & 0.53 & 10.95 \\
\hline & total: & 100.00 & & 100.00 \\
\hline \multirow{5}{*}{ (c) $\mathrm{CS}-\mathrm{C}$} & $\mathrm{C}$ & 23.71 & 1.28 & 35.55 \\
\hline & $\mathrm{O}$ & 41.88 & 0.76 & 47.14 \\
\hline & $\mathrm{S}$ & 16.37 & 0.31 & 9.20 \\
\hline & $\mathrm{Ca}$ & 18.04 & 0.34 & 8.11 \\
\hline & total: & 100.00 & & 100.00 \\
\hline
\end{tabular}

Figure S2. Elements content table from EDX spectra of samples CS-T (a), CS-S (b) and CS-C (c) 